\title{
O IMAGINÁRIO SOBRE A CAATINGA REPRESENTADA NOS DESENHOS INFANTIS DE ESTUDANTES DO NORDESTE DO BRASIL
}

\author{
Ricardo Bitencourt ${ }^{1}$ \\ Juracy Marques ${ }^{2}$ \\ Geraldo Moura ${ }^{3}$
}

Resumo: Este trabalho teve como objetivo analisar as ideias sobre a Caatinga representadas em desenhos feitos por estudantes do $5^{\circ}$ ano do ensino fundamental. A pesquisa foi desenvolvida em duas escolas da cidade de Senhor do Bonfim-BA, uma pública e outra privada. Foi solicitado às crianças que elaborassem desenhos referentes à Caatinga. Além dos desenhos, também foram coletadas descrições desses para que a interpretação lúdica não fugisse à ideia original que tiveram seus autores a respeito da Caatinga. Apresentam descrições sobre flora e fauna sem muita diversidade, dando mais destaque à primeira. Aponta para o uso de desenhos como uma ferramenta consistente para a captação das percepções de crianças e adolescentes sobre seus espaços de vida, como é o caso da Caatinga.

Palavras-chave: Percepção |Ambiental; Semiárido; Educação Ambiental; Representações Sociais.

${ }^{1}$ IF Sertão Pernambucano - Campus Petrolina. E-mail: ricardo.bitencourt@gmail.com

${ }^{2}$ Universidade do Estado da Bahia - Campus - III. E-mail: juracymarquesyahoo.com.br.

${ }^{3}$ Universidade Federal Rural de Pernambuco-UFRPE. E-mail: geraldojbm@yahoo.com.br. 


\section{Introdução}

Atualmente torna-se iminente a formulação de planos de gestão e manejo mais eficientes à conservação da biodiversidade e dos ecossistemas associados (COLLI et al., 2003). Neste contexto, estudos que visem entender como que as comunidades concebem os recursos naturais, transformam-se em excelentes indicadores para se entender o status de conservação desses bens naturais. Tais demandas destacam os problemas ambientais, o que pode ser evidenciado em encontros como "RIO + 20" realizada em junho 2012. O Brasil é bastante privilegiado quanto à biodiversidade, possibilitado pela reunião de zonas biogeográficas como a Floresta Amazônica, Pantanal, Cerrado, Caatinga e Mata Atlântica, além de uma variedade de ecossistemas que incluem recifes, dunas, manguezais, lagoas, estuários e pântanos (ALVES; SILVA; VASCONCELOS, 2009). A Caatinga passa por um processo de degradação que compromete a manutenção de seu já frágil equilíbrio ecológico (ALBUQUERQUE et al., 2001), daí, por tanto, faz-se necessária a abordagem dessa temática nos diversos espaços de debate.

A Caatinga ocupa uma área de $844.453 \mathrm{Km}^{2}$, o que equivale a 9,92\% da área total do Brasil, estendedo-se pelos estados do Ceará (100\%), Bahia (54\%), Paraíba (92\%), (83\%), Piauí (63\%), Rio Grande do Norte (95\%), Alagoas (48\%), Sergipe (49\%) e Maranhão (1\%) nordeste, além de Minas Gerais (2\%), na região sudeste, destacando-se ainda por ser um bioma exclusivamente brasileiro, abrigando uma população de cerca de 23 milhões de pessoas (ABÍLIO; FLORENTINO; RUFFO, 2010; SANTANA; SOUTO, 2006).

Por essa constatação, percebe-se que a representação sobre o lugar é vital para a manutenção de uma dinâmica que respeite o meio ambiente e que, ao mesmo tempo, possibilite o desenvolvimento local sem comprometer o meio ambiente (LUCENA; XAVIER, 2011; SILVA; CANDIDO; FREIRE 2009). Exemplos de ações institucionais de conservação que são comumente realizadas são as criações de Unidades de Conservação, de proteção integral ou parcial, que, geralmente, tem como característica o isolamento de áreas a serem protegidas.

Não há um consenso sobre esse tipo de ação já que para alguns pesquisadores as ações antrópicas, mesmo em áreas como essas, ainda são uma ameaça constante (BEZERRA et al., 2008). Outros, como Diegues, (1996) creem que essa proteção no sentindo da proibição do acesso não reflete, de maneira geral, uma ato muito eficaz, já que, no caso da relação desses espaços com Povos e Comunidades tradicionais, por exemplo, é possível verificar uma relação harmoniosa entre biodiversidade e o uso sustentável através de "atividades econômicas de pequena escala, como agricultura, pesca, coleta e artesanato" (DIEGUES, 1996, p.87).

O descuido com a Caatinga torna-a vulnerável de forma a acelerar processos que podem comprometer a manutenção da sua biodiversidade, ações essas, essencialmente provocadas por atividades humanas (SILVA; CANDIDO 2009). Nessa direção, a observação do pensamento das novas

revista brasileira educação ambiental 
gerações é um potencial indicador quando se pretende atuar de forma esclarecedora em relação ao meio ambiente, uma vez que a escola tem um papel fundamental na formação de das novas gerações (LUZ et al., 2012).

Deve-se levar em consideração que o ambiente escolar propicia uma visualização da diversidade de organização dos alunos, especialmente no que se refere à cultura (GASPAROTTI, 2011). Além disso, a criança não possui um papel passivo dentro do ambiente escolar atuando numa mediação de saberes gerenciando fragmentos de conceitos do cotidiano pedagógico no qual está inserida (SARAVALI, 2010) o que demonstra o reconhecimento, mesmo que às vezes criticado, do papel da escola como transmissora de conhecimentos através do ato de ensinar (MENDONÇA, 2011).

Há entre os fundamentos da ecoalfabetização, da educação ambiental e da ecopedagogia, a vital percepção de que as questões ligadas à conservação da biodiversidade e as bases da ecologia dos ecossistemas, nascem e desaguam na educação, cujas sementes são as escolas e os pensamentos, as ideias, os espíritos dos alunos (as) (MARQUES, 2012). Assim, corroborando, Viga et al. (1999, p.64) pontuam que "Education for a population's development should be integral and perennial". Por fim, as crianças são um grupo muito especial para esse tipo de trabalho, pois são suscetíveis a fatores especialmente em sua relação do o meio ambiente (SILVA et al. 2010, p.196).

De ante do exposto, então, pretende-se nesse trabalho revelar a percepção de crianças e adolescentes sobre a Caatinga, lugar onde vivem, objetivando discutir as expressões reportadas através dos desenhos e a relação existente com os discursos dos seus respectivos autores e em que medida essas representações são tradutoras de bases para a conservação ou não desse importante bioma brasileiro.

\section{Material e Métodos}

\section{Público Alvo}

Realizou-se a coleta de dados durante o mês de Junho de 2012, onde participaram 37 crianças/adolescentes de 08 a 14 anos (Figura 1) estudantes de duas escolas no município de Senhor do Bonfim, Bahia. O Município localiza-se na região norte do estado, dentro do território de identidade do Piemonte Norte do Itapicuru, a $375 \mathrm{~km}$ da capital do estado. Dados coletados no IBGE (2012) nos mostram que o município possui população de 74.419 habitantes distribuída numa área de Caatinga de $827 \mathrm{Km}^{2}$.

Todas as crianças e adolescentes estavam matriculadas, no $5^{\circ}$ ano (antiga 4a série) em duas escolas, uma pública, de regime integral de trabalho e outra privada, no turno matutino, abordadas em um dia normal de aula. Foi apresentado aos responsáveis pelos alunos o Termo Livre Esclarecimento onde explicamos a atividade e pudemos garantir o sigilo sobre a identidade dos participantes. 


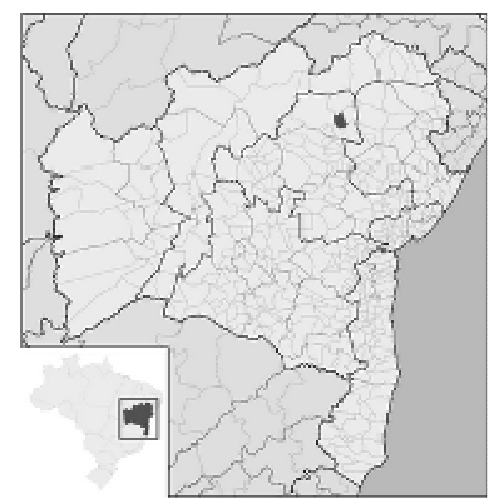

Figura 1: Localização geográfica da área de estudo, destacando o Estado da Bahia e o Município de Senhor do Bonfim cujas coordenadas são lat. 10 S 27' 41" log.40 W 11' 22".

Fonte: IBGE, 2012.

A opção por alunos do $5^{\circ}$ ano se deu pelo fato de estarem em um momento de várias transições, como para o ensino fundamental II, saída da infância e passagem para a adolescência e demonstrarem maturidade para a representação de suas ideias, que torna possível a realização desse tipo de atividade (SALLES, 2005; CUNHA; ALMEIDA, 2003). No desenho, a criança transmite uma construção simbólica sobre sua realidade e sobre sua experiência subjetiva, registrando o que é significativo (PILLOTTO; SILVA; MOGNOL, 2012).

\section{Metodologia}

Para coleta das percepções dos alunos sobre a Caatinga utilizou-se como estratégia os desenhos. Segundo Goldberg, Yunes e Freitas, (2012 p. 105) sejam pinturas, como as rupestres, ou mesmo gravuras, "desenhar, contemplar e criar poetizam o cotidiano, ressignificam as atividades cotidianas, constroem novos sentidos para a vida". O desenho como ferramenta de percepção do sentido e do favorecimento do diálogo se torna uma ferramenta salutar no trabalho com crianças e adolescentes quando o objetivo é tentar perceber a essência de seus conceitos sobre determinados assuntos, já que " 0 desenho nos mostra a maneira como a criança, através das coisas, vive os significados simbólicos que ela lhes atribui. É a reunião de seu mundo imaginário que se reflete no seu desenho" (GOLDBERG; YUNES; FREITAS, 2012, p.102).

A atividade foi realizada, sob nossa supervisão e por uma professora comum às duas escolas. Todos os alunos receberam uma folha A4 em branca e tiveram à disposição os mesmos materiais para a elaboração dos desenhos. As produções foram identificadas apenas com a idade sexo de cada aluno, que receberam como orientação apenas o pedido para que desenhassem a Caatinga, sem qualquer limitação de tempo para isso.

Junto ao pedido de desenho, solicitou-se aos mesmos que descrevessem no verso da atividade o que estavam desenhando para que não 
corrêssemos o risco de gerar um entendimento diferente do discurso pretendido e para confrontar a perspectiva da imagem com a intenção do autor.

\section{Resultados e Discussão}

Foram analisados os trabalhos de 37 alunos, sendo 17 de uma escola particular e 20 de uma escola pública, o que proporcionou uma faixa etária variando dos 08 aos 14 anos (Figura 2).

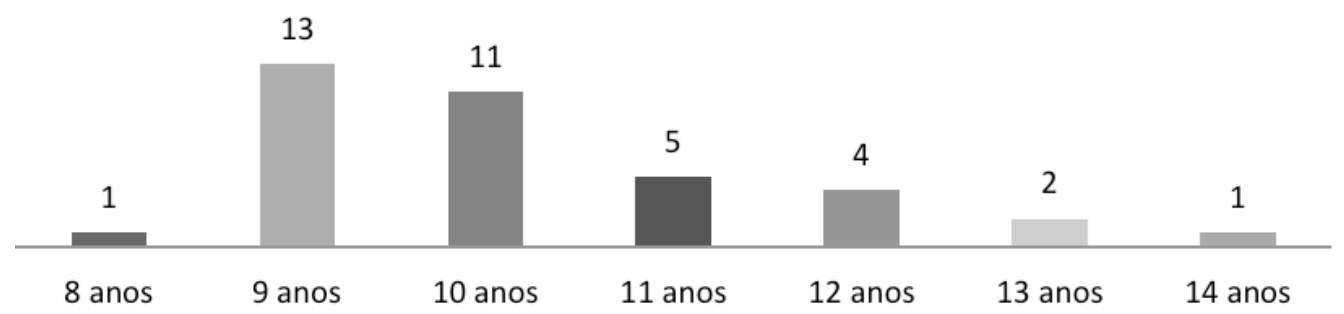

Figura 2: Idade dos alunos do $5^{\circ}$ ano de dois colégios, um da rede privada e outro da rede pública participantes da pesquisa, Senhor do Bonfim-BA.

Nenhum aluno se recusou a participar da atividade sugerida. Chamounos a atenção o fato de poucos desenhos trazerem representações de figuras humanas, o que ocorreu em apenas 09 dos 37 trabalhos, o que revela, segundo Oliveira e Fonseca (2011), uma tendência naturalista de conceituação da natureza ligando-a efetivamente à fauna e à flora. Vale ressaltar que, diferentemente dos desenhos da escola particular (Tabela 1 e Figuras 3 e 4) onde dos 17 trabalhos 13 tiverem esse tipo de representação, em nenhum dos desenhos elaborados pelos alunos da escola pública (Tabela 2 e Figura 5) foi inserida qualquer representação de moradia. No debate sobre natureza e sociedade é lugar comum a separação do sujeito, enquanto ser social, das percepções sobre a natureza. Entretanto, perceber o meio ambiente é entender as complexas relações que envolvem sociedade e natureza, para além das concepções reducionistas e biologizantes (OLIVEIRA; FONSECA 2011, p.236) e, nessa direção, devem instigar o debate sobre os efeitos continuados, e cumulativos das ações antrópicas que seguem o modelo de vida propagado pela a humanidade (SANTOS, 1992 p.97), o que explica a aparição de residências nas produções, que é, de fato, uma marca da presença humana no sentido de explorador do ambiente.

Os alunos que não quiseram, por qualquer motivo, escrever no verso, puderam relatar à professora para que a mesma o fizesse, garantindo que todos descrevessem seu desenho, já que, segundo Pereira (2012, p.3) é "a base da linguagem gráfica constituída pelo desenho". Esse relato era realizado reservadamente para não influenciar a descrição dos outros participantes. 
Tabela 1: Descrições feitas pelos alunos da escola particular referente aos seus desenhos sobre a Caatinga na cidade de Senhor do Bonfim (BA).

\begin{tabular}{|c|c|c|c|}
\hline COD & IDADE & SEXO & DESCRIÇÃO \\
\hline P01 & 9 & M & "A imagi que eu fis e um imagi da ceca do nodete" \\
\hline P02 & 9 & M & $\begin{array}{l}\text { "Eu desenhei a seca do nordeste e eu desenhei também tudo que tem na } \\
\text { seca." }\end{array}$ \\
\hline P03 & 10 & M & "O que eu diseiu foi uma casa e uma cisterna e mandacaru e uma palma". \\
\hline P04 & 10 & M & "Nuve, Sal, Mandacaru, casa sisterna, cavalo." \\
\hline P05 & 11 & M & "pé de nada, galinha, passarinho pé de imbu, uma casa." \\
\hline P06 & 12 & M & $\begin{array}{l}\text { "Urubus, arvores, igreja, uma casa, umas vacas morta, camelo, sizau, } \\
\text { mandacaru" }\end{array}$ \\
\hline P07 & 10 & M & "o sol triste, os urubus comendo carnissa." \\
\hline P08 & 9 & M & $\begin{array}{l}\text { "É uma casinha na catinga com a natureza os animais, rios o céu todas as } \\
\text { coisas mais lindas da natureza" }\end{array}$ \\
\hline P09 & 13 & $\mathrm{~F}$ & $\begin{array}{l}\text { "É uma casinha na cantinga com o natureza, os animais, os rios, o ceu as } \\
\text { coisas mais linda da natureza." }\end{array}$ \\
\hline P10 & 9 & $\mathrm{~F}$ & $\begin{array}{l}\text { "Eu desenhei um semiarido da Caatinga e eu fiz alguns detalhes } \\
\text { representando a seca na catinga e o sol está muito quente." }\end{array}$ \\
\hline P11 & 9 & $\mathrm{~F}$ & $\begin{array}{l}\text { "Ao fazer esse desenho eu aprendi a desenhar augumas plantas da } \\
\text { Caatinga e so desenhei umas palmas e uma árvore seca." }\end{array}$ \\
\hline $\mathrm{P} 12$ & 10 & $\mathrm{~F}$ & $\begin{array}{l}\text { "Eu fiz um porco do sertão, fiz as naturalidade que tem nele, fiz uma casa } \\
\text { de tijolos que raramente nós vemos umas delas, fiz o sol lindop e ardente } \\
\text { do sertão e só imagino o sertão assim." }\end{array}$ \\
\hline P13 & 10 & $\mathrm{~F}$ & $\begin{array}{l}\text { "A catinga pe seca purisso tudo nela é diferente, te cactos, casas de } \\
\text { barbante, chão seco, árvores secas, tudo é seco, com moradores e } \\
\text { animais." }\end{array}$ \\
\hline P14 & 11 & $\mathrm{~F}$ & $\begin{array}{l}\text { "Eu fiz esse dezenho representado u nordeste eu dezenhei um madacaru, } \\
\text { fis um sol, nuves, uma borboleta, frores, rozas, garaxo, passaro." }\end{array}$ \\
\hline P15 & 13 & $\mathrm{~F}$ & $\begin{array}{l}\text { "Eu desenho flores, mandacaro, borboletas, as nuves e o sol, os matos } \\
\text { verdes." }\end{array}$ \\
\hline P16 & 12 & $\mathrm{~F}$ & "Eu desenho a nordeste, a casa" \\
\hline $\mathrm{P} 17$ & 12 & $\mathrm{~F}$ & "Nesse desenho eu fiz uma casa de taipa, uma cisterna etc." \\
\hline
\end{tabular}

Fonte: Autoria própria.

Para Silva (2012, p.1) as produções na literatura científica apontam o grafismo infantil como uma atividade natural e espontânea. Essas representações, segundo Moscovici (2005, p.37) nos possibilita elaborar melhor o olhar sobre as estruturas que ancoram as representações significantes do sujeito social, já que a representação que temos de algo não está diretamente relacionada à nossa maneira de pensar e, contrariamente, porque nossa maneira de pensar e o que pensamos depende de tais representações. 
Tabela 02: Descrições feitas pelos alunos da escola pública referente aos seus desenhos sobre a Caatinga na cidade de Senhor do Bonfim (BA).

\section{COD IDADE SEXO DESCRIÇÃO}

\begin{tabular}{|c|c|c|c|}
\hline N01 & 9 & M & $\begin{array}{l}\text { "Eu dezenhei a caatiga com com o sol bem quente, com as nuvens, os } \\
\text { urubus, o licurizeiro, a arvore com frutas e a lagoa co os peixe e a grama } \\
\text { bem verdinha." }\end{array}$ \\
\hline N02 & 10 & M & $\begin{array}{l}\text { "Da sol e chuva, nuvem pé de umbuzeiro, pé de mandacaru, pé de } \\
\text { nicurizeiro, porteira, eu e meu pai." }\end{array}$ \\
\hline N03 & 9 & M & $\begin{array}{l}\text { "Eu desenhei água e um pé de maçã, pé de côco, chuva e o sol. Tudo isso } \\
\text { é uma Caatinga" }\end{array}$ \\
\hline N04 & 9 & $\mathrm{~F}$ & "Pé de flor, pé de licuri, árvore" \\
\hline N05 & 9 & M & "Serra, coceiro, ouricuri, rio, arvore, pau-brasil." \\
\hline N06 & 9 & M & "Mato, pé de coqueiro, árvores, pé de umbu." \\
\hline N07 & 12 & M & "Pé de umbu, pé de licuri, Mandacaru, Bode, Pássaro, chuva, sol." \\
\hline N08 & 10 & M & $\begin{array}{l}\text { "Eu desenhei a paisagem da caatinha onde predomina umbuzeiro, } \\
\text { mandacaru, sol quente, ouricuri." }\end{array}$ \\
\hline N09 & 9 & M & $\begin{array}{l}\text { "Eu fiz pé de imbu i fz pe de mandacaru é fis pe de coco e fis pe de ouricuri } \\
\text { e fis uma vaca i um mato" }\end{array}$ \\
\hline N10 & 10 & M & "Desenhei três pés de licuri, um pé de mandacaru, um sol e uma nuvem" \\
\hline N11 & 10 & M & $\begin{array}{l}\text { "O desenho que fiz apresenta a paisagem da Caatinga onde se faz } \\
\text { presente plantas, como: umbuzeiro, mandacaru, ouricuri, todas elas } \\
\text { caracterizam a Caatinga, o lugar onde vivo." }\end{array}$ \\
\hline N12 & 14 & $\mathrm{~F}$ & "Ouricuri, mandacaru, sol" \\
\hline N13 & 8 & $\mathrm{~F}$ & "Flor, côco, árvores de flores, licuri, coração, sapo e flor." \\
\hline N14 & 11 & $\mathrm{~F}$ & "Ouricuri, alfo, cala, calcipi, peqela." \\
\hline N15 & 9 & $\mathrm{~F}$ & $\begin{array}{l}\text { "Eu desenhei este desenho porque eu sei qui na catinga tei isso sol quete } \\
\text { mato, pé de ouricuri, tem rios esa é minha história." }\end{array}$ \\
\hline N16 & 10 & $\mathrm{~F}$ & "Mato, sol, árvore, rio, pé de maçã." \\
\hline N17 & 10 & $\mathrm{~F}$ & "Ouricuri, mandacaru, umbu, coqueiro, mato seco, tanque." \\
\hline N18 & 11 & $\mathrm{~F}$ & $\begin{array}{l}\text { "Esta arte foi minha. Isto é que eu acho que tem na catinga tem mais outros } \\
\text { varis tipos de arvore. Este é o pé de umbu, este é o pé de mandacaru; meu } \\
\text { tanque" }\end{array}$ \\
\hline N19 & 9 & $\mathrm{~F}$ & "Coco, caju, ouricuri" \\
\hline N20 & 11 & $\mathrm{~F}$ & "Ouricuri, imbuzeiro" \\
\hline
\end{tabular}

Fonte: Autoria própria.

Quando a criança desenha, a importância desse fazer reside no fato de que ela se permite revelar e reconhecer cada objeto representado, não numa perspectiva de cópia do real, mas na explicitação do imaginário e do potencialmente invisível aos adultos que se encontra numa perspectiva do simbolismo. "Se um detalhe invisível permite fazer um reconhecimento melhor do objeto, ele será representado contra toda a aparência" (GRUBITS, 2003 p. 98).

Já o adulto, ao contrário, desenvolve e estabelece vínculos estéticos com sua produção visual, diferentemente da criança que se revela na própria produção. "Se todos os indivíduos continuassem o processo de 
desenvolvimento gráfico, passando por todas as etapas, com certeza saberiam se expressar a partir de manifestações artísticas" (GOLDBERG; YUNES; FREITAS 2012, p.102).

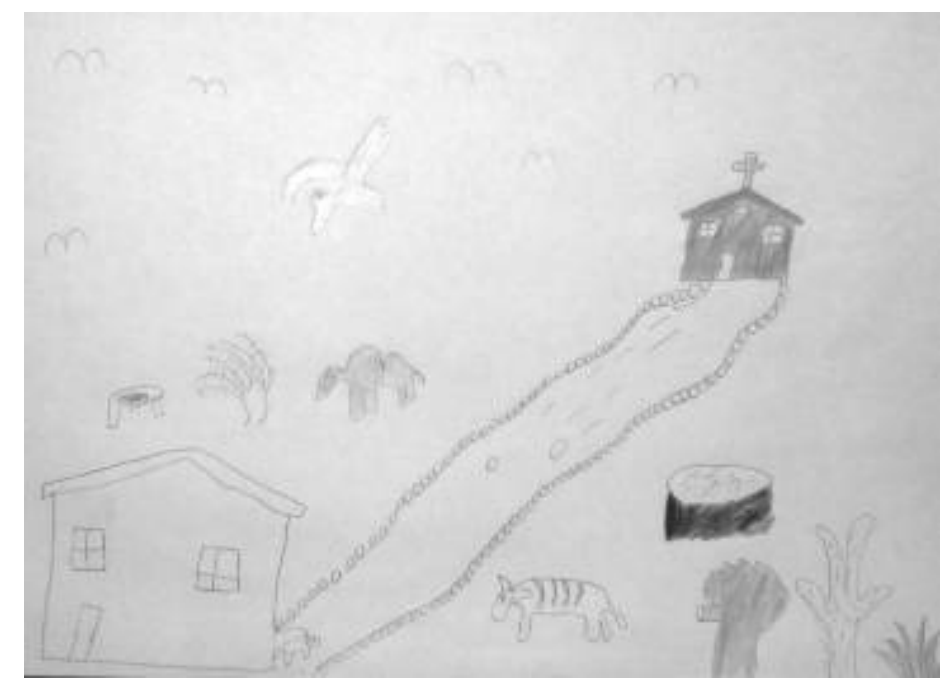

Figura 3: Desenho (P06) feito por um aluno de 12 anos da escola particular com a seguinte descrição no verso: "Urubus, arvores, igreja, uma casa, umas vacas morta, camelo, sizau, mandacaru"

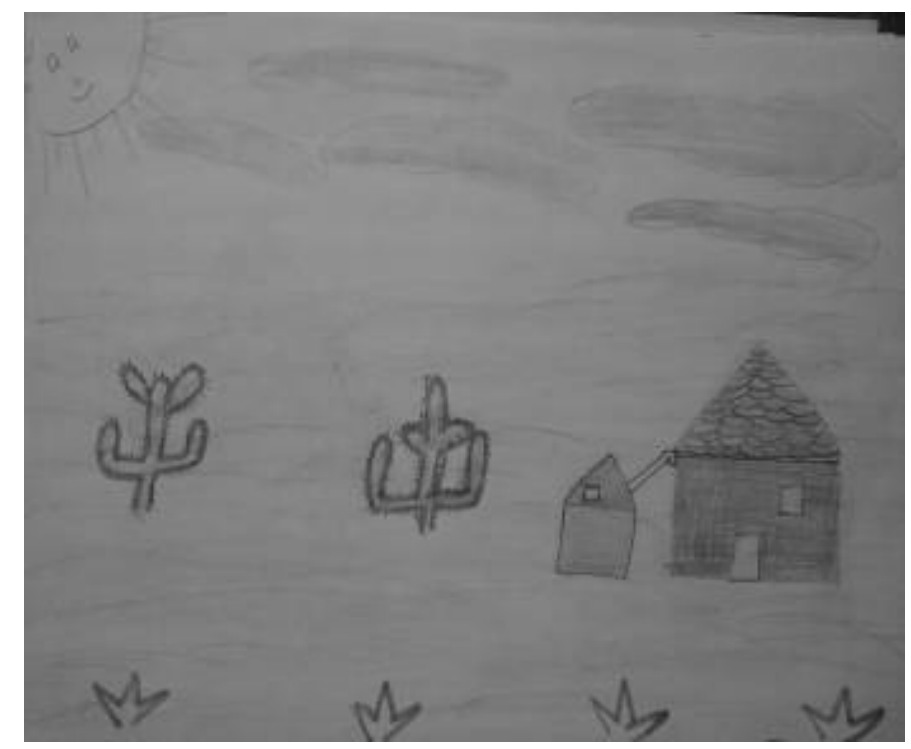

Figura 5: Desenho (P16) feito por uma aluna de 12 anos da escola particular com a seguinte descrição no verso: "Eu desenho a nordeste, a casa". 


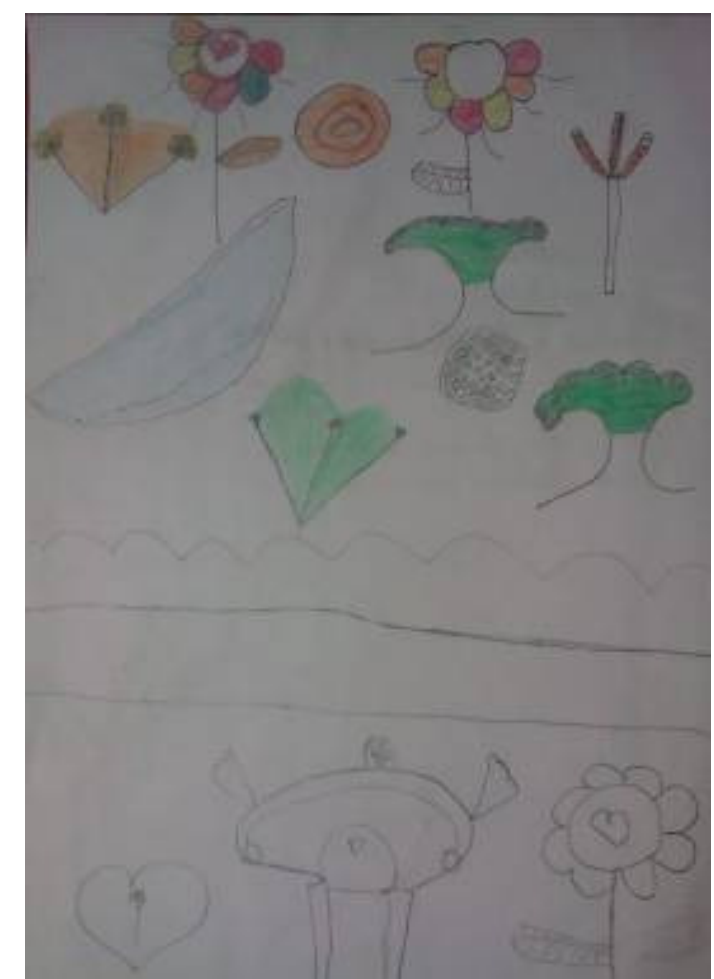

Figura 5: Desenho (N13) feito por uma aluna de 08 anos da escola pública com a seguinte descrição no verso: "Flor, côco, árvores de flores, licuri, coração, sapo e flor."

No geral, os alunos se limitaram a descrever as imagens construídas em seus trabalhos fazendo poucas referências de classificação como positiva ou negativa sobre a Caatinga. Observou-se que $11 \%$ dos relatos deram ênfase à seca como algo negativo presente na Caatinga, entretanto, $89 \%$ demonstraram aspectos de convivência e de classificação do lugar de moradia (Figura 6).

No trabalho de Araújo e Sobrinho (2009) podemos constatar a importância do conhecimento sobre a realidade local e a potencialização de mecanismos que favorecem 0 desenvolvimento de estratégias para a convivência com a seca. Para Silva (2003) indústria da seca foi utilizada por muito tempo como um argumento para manutenção de uma ideia desvalorizadora da Caatinga e das possibilidades de um avanço na convivência com as intempéries. Ainda assim, é possível perceber nos relatos espontâneos uma mensagem que não negativa ou positiva a Caatinga e revela processos de melhoria nas estratégias de convivência. 


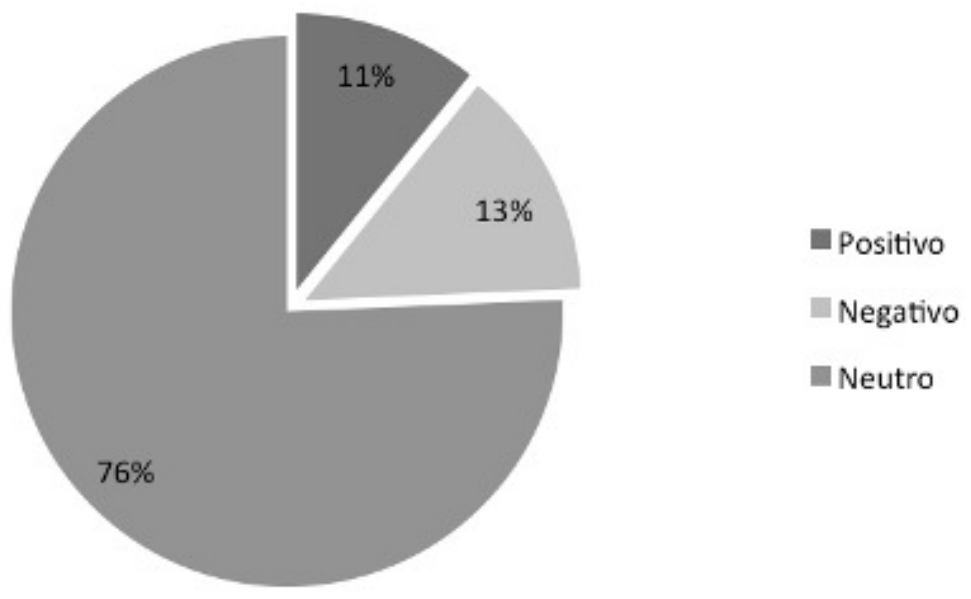

Figura 6: Classificações positivas, negativas ou neutras interpretadas através da elaboração dos desenhos sobre a Caatinga e seus respectivos relatos.

Sobre a flora (Figura 7), percebeu-se um grande destaque na representação de umbuzeiros, ouricuri e mandacaru. Em menor quantidade, constatou-se outras representações como o sisal, palma, caju, flores e maçã. A representação mais presente sobre a biodiversidade da Caatinga é através da flora (OLIVEIRA \& FONSECA, 2011). Além das possibilidades de uso na alimentação algumas espécies, como o umbuzeiro, são consideradas sagradas pelo sertanejo, como é possível perceber no trabalho de Brasileiro (2009).
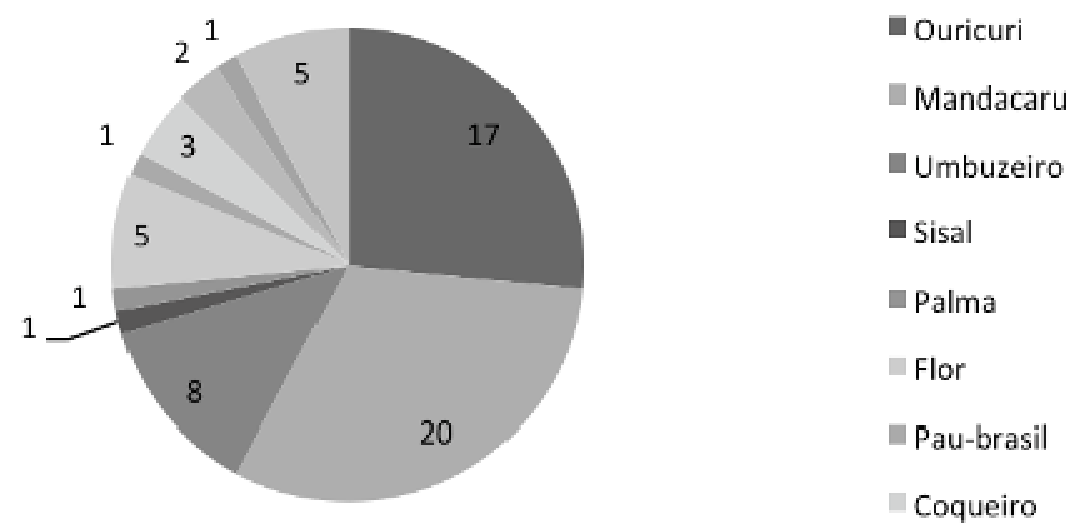

Figura 7: Vegetação representada nos desenhos e identificada através das descrições realizadas pelos alunos.

Revbea, São Paulo, V.9, Nº 2: 254-269, 2014. 
Outras espécies típicas como a umburana, caraibeira não foram citadas. Em alguns trabalhos a vegetação é classificada pelos alunos apenas como "árvore" ou "mato". Vale lembrar que esse tipo de caracterização só foi possível por causa da descrição feita no verso dos desenhos. Quanto à fauna (Figura 8) tivemos uma predominância da citação de aves como urubus, galinhas e outros pássaros não identificados. Em poucos casos apareceram nos trabalhos animais como bode, vaca, cavalo, peixes e borboletas.
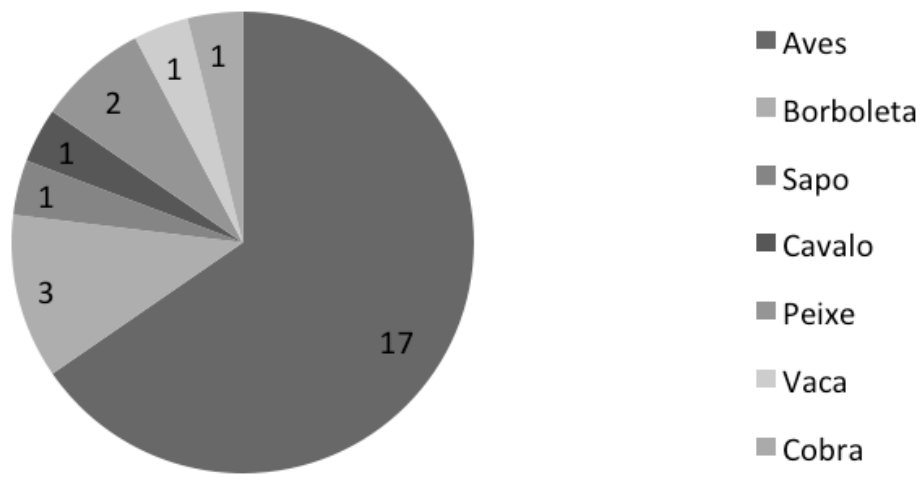

Figura 8: Animais representados e identificados através das descrições realizadas pelos alunos.

Observando os trabalhos de Cardoso e Queiroz (2008) e Andrade (2009) é possível verificar a imensa biodiversidade que possui a Caatinga. Entretanto, historicamente o bioma Caatinga foi representado e divulgado como um lugar "feio", "inóspito", "pobre em biodiversidade e endemismo". Trata-se de um dos Biomas mais diversos do mundo em condições de clima e solo (MARQUES, 2007), único totalmente brasileiro, o que confere valores biológicos e econômicos significativos para o Brasil e América Latina.

Essas equivocadas representações negativas da Caatinga atravessaram os tempos e ainda não foram quebradas pelas ações educativas das escolas brasileiras, particularmente do Semiárido, presentes, como mostra este trabalho, nas mentes, no imaginário, nos sentimentos das nossas crianças e adolescentes. Afinal, como sugere Kidner (1999, p.15), "nature's structure is, in a healthy world, that of the unconscious, invoking multiple meanings, ambiguity, metaphor, and symbolism".

Percebe-se que o conhecimento sobre essa diversidade é muito pequeno, conforme pontua Barbosa \& Barbosa (2011), quando avalia a classificação dada à Caatinga por alunos paraibanos, como um bioma "pobre $e$ sem diversidade de vida" (BARBOSA; BARBOSA, 2011 p.179). 
Todos os desenhos, mesmo os mais frágeis de descrição, revelam a ideia de cada um sobre elementos da Caatinga. Cada representação nos passa uma mensagem de uma função no espaço ou de representação de uma imagem de convivência com a Caatinga. "O desenho, ao dar forma ao pensamento, parece possibilitar o exercício do conhecimento, com a progressiva construção de conceito do objeto focalizado" (PEREIRA, 2012 p.16).

As cores utilizadas tentam retratar o mais próximo cada espécie de planta citada nos discursos. Mesmo com esse esforço salutar, ressalta-se que, mesmo sendo inseridas imagens de animais, e até humanas, ainda domina a paisagem imagética de uma valorização do bioma a partir da flora. Ainda assim, a imagem da interferência humana está presente, seja com o desenho do próprio homem e/ou mulher, seja com a representação de lugar, através da inserção de edificações, igrejas, veículos. Barbosa e Barbosa (2011) pontuam que, lamentavelmente, as ações antrópicas contribuem para a degradação da Caatinga.

É possível detectar em alguns desenhos que a representação sobre a Caatinga é muito mais explorada através sua flora. $\mathrm{O}$ que nos leva a discutir que ainda prevalece uma visão estigmatiza sobre a sua vegetação, que é peculiar, onde na época seca, mais comum, tem a maioria da vegetação com aspecto esbranquiçado, desprovida de folhas, com galhos fortemente retorcidos e dotados de espinhos. Dessa forma, ao focar os debates sobre a sua vegetação, outros aspectos fundamentais são deixados de lado, como a fauna que compõe esse Bioma. Assim, o grande desafio é a elaboração de uma visão complexa de um todo, o que significaria "abrir nossas percepções para um mundo complexo, vivo, dinâmico e intenso" (GOLDBERG; YUNES; FREITAS, 2012, p. 98).

As figuras, com poucas exceções, representam o imaginário das crianças, tendo como principal estímulo à realidade local da Caatinga, ou seja, o que eles conhecem do bioma, mesmo sendo alunos de escolas situadas na área urbana. Chama a atenção representações em relação ao sol, que, nos desenhos, aparece expressando sentimentos de alegria, tristeza ou raiva, que, na verdade, são construções do sentido de seus autores, pois, segundo Pereira (2012, p.3), "a percepção do objeto, no desenho, corresponde à atribuição de sentido dada pela criança, constituindo-se realidade conceituada, e não material".

$\mathrm{Na}$ representação da fauna, seja selvagem ou doméstica, percebe-se que a imagem de animais apenas compõe uma paisagem dominada pela flora ou pela ideia de moradia, reforçada no aparecimento desses animais geralmente numa condição de serviço ou para reforçar um cotidiano de morte de animais, resultado da falta de água. Para Ceríaco (2012) é incomum a representação de outros animais, como répteis ou anfíbios, já que nem todas as espécies de animais tem a sorte de ser apreciadas pelos humanos. 
Por fim, chama a atenção à representação da convivência com a seca, o que nos remete a uma valorização do lugar que se vive. Apenas em um caso foi representada a ideia de saída da Caatinga com a representação de um carro (parecido com o pau-de-arara). Na grande parte dos trabalhos, detalhes como as cisternas sugerem que as representações dos alunos um processo de convivência com as características da Caatinga, como a falta de chuvas, e apontam para a popularização de tecnologias para o favorecimento do homem como parte integrante do bioma. Segundo Silva (2003) as ações em direcionadas à região da Caatinga, especialmente para manutenção do homem do campo, devem ser perenes e não se resumir a ações emergenciais. Necessita-se a consolidação de políticas públicas para acesso a recursos e estruturas que facilitem a vida e a produção, especialmente da agricultura familiar.

\section{Considerações Finais}

É imprescindível ficar atento aos relatos infantis, pois, em geral, deixam escapar detalhes sobre o seu contexto que a observação apenas do desenho não é capaz de percebe. O que se desenha extrapola a realidade geral que normalmente encobre as particularidades da fala do sujeito, em seu contexto individual, especialmente sobre a Caatinga.

Em alguns episódios descritos toda a diversidade da Caatinga é deixada de lado para manutenção da ideia da Caatinga como um lugar inóspito. Entretanto, revela-se, também, o esforço para a caracterização das estratégias complexas de convivência no Semiárido, e, especialmente, com a seca, que são adotadas no seu cotidiano.

Por fim, os dados demonstra-se a eficiência da estratégia de utilização dos desenhos na coleta desse tipo de informação com crianças e adolescentes e como essas impressões podem ajudar a entender a relação desses com o espaço em que vivem. Além disso, é possível sinalizar para a importância do espaço escolar como mediador de debates, principalmente no que diz respeito à Caatinga, e como a caatinga, como lugar, é representada no discurso e na representação de imagem dos indivíduos envolvidos.

\section{Referências}

ALBUQUERQUE A.W., LOMBARDI-NETO, F.; SRINIVASAN, V.S. Efeito do desmatamento da Caatinga sobre as perdas de solo e água de um luvissolo em Sumé (PB). Revista Brasileira de Ciência do Solo, vol. 25, núm. 1, 2001, pp. 121-128 Sociedade Brasileira de Ciência do Solo. Viçosa, Brasil

ABÍLIO, F.J.P.; FLORENTINO, H.S.; RUFFO, T.L.M. Educação Ambiental no Bioma Caatinga: formação continuada de professores de escolas públicas de São João do Cariri, Paraíba. Pesquisa em Educação Ambiental, vol. 5, n. 1 pp. 171-193, 2010. 
ALMEIDA, A.M.O.; CUNHA, G.G. Representações sociais do desenvolvimento humano. Psicol. Reflex. Crit. [online]. vol.16, n.1, pp. 147-155., 2003.

ALVES, L.I.F.; SILVA, M.M.P.; VASCONCELOS, K.J.C. Visão de comunidades rurais em Juazeirinho/PB referente à extinção da biodiversidade da Caatinga. Revista Caatinga. 22 (1), 2009,p. 180-186.

ANDRADE, L.A.; FABRICANTE, J.R.; OLIVEIRA, F.X. Invasão biológica por Prosopis juliflora (Sw.) DC.: impactos sobre a diversidade e a estrutura do componente arbustivo-arbóreo da Caatinga no Estado do Rio Grande do Norte, Brasil. Acta Bot. Bras. [online]. 2009, vol.23, n.4, 2009, pp. 935-943.

ARAÚJO, C.S.; SOBRINHO, J.F. O bioma Caatinga no entendimento dos alunos da rede pública de ensino da cidade de Sobral - Ceará. Revista Homem, Espaço e Tempo, Centro de Ciências Humanas-CCH / Universidade Estadual Vale do Acaraú-UVA, 2009.

BARBOSA, J.A.A.; BARBOSA, R.K.V.C. Visões de um semiárido: a diversidade biológica da Caatinga na óptica de alunos da rede pública de ensino no agreste paraibano. BIOFAR - Revista de biologia e farmácia, Vol. 06 № 01 pp. 176184. ISSN 1983-4209

BEZERRA, T.M.O.; FELICIANO, A.L.P.; ALVES, A.G.C. Percepção ambiental de alunos e professores do entorno da Estação Ecológica de Caetés - Região Metropolitana do Recife-PE. Revista Biotemas, Vol. 21 (1): 147-160. UFSC, 2008.

BRASIL. Ministério do Planejamento, Orçamento e Gestão. Instituto Brasileiro de Geografia e Estatística. Mapa de Biomas do Brasil e o Mapa de Vegetação do Brasil, em comemoração ao Dia Mundial da Biodiversidade. Disponível em: $<$ http://www.ibge.gov.br/home/presidencia/noticias/noticia visualiza.php?id noti cia $=169>$ Acesso em: 30/07/2012

BRASIL. Ministério do Meio Ambiente. Secretaria de Biodiversidade e Florestas SBF/MMA. Projeto de monitoramento do desmatamento dos biomas brasileiros por satélite: Monitoramento da Caatinga. Disponível em: $<$ http://siscom.ibama.gov.br/monitorabiomas/Caatinga/Caatinga.htm $>$ Acesso em: 30/07/2012

BRASILEIRO, R.S. Alternativas de desenvolvimento sustentável no semiárido nordestino: da degradação à conservação. Scientia Plena, Vol. 5, no. 5, 2009.

CARDOSO, D.B.OS.; QUEIROZ, L.P. Floristic composition of Seasonally Dry tropical Forest fragments in Central Bahia, Northeastern Brazil. J. Bot. Res. Inst. Texas 2(1): 551 - 573. 2008.

CERÍACO, L.M.P. Human attitudes towards herpetofauna: The influence of folklore and negative values on the conservation of amphibians and reptiles in Portugal. Journal of Ethnobiology and Ethnomedicine. $n^{\circ} 8,7000-554$, Évora, Portugal. Disponível em: <http://www.ethnobiomed.com/content/8/1/8> Acesso em 30/07/2012 
COLLI, G.R.; et al. A fragmentação dos ecossistemas e a biodiversidade brasileira: Uma síntese. Pp.: 317-324. In: RAMBALDI, D.M.; OLIVEIRA, D.A.S. (EDS.). Fragmentação de ecossistemas: Causas, efeitos sobre a biodiversidade e recomendações de políticas públicas. Ministério do Meio Ambiente/Secretaria de Biodiversidade e Florestas, Brasília, 2003.

DIEGUES, A.C.S. (1996) O mito da natureza intocada. São Paulo: Hucitec. 1996.

GASPAROTTI, F.N. Interculturalidade e o papel da escola na atualidade: reflexões a partir do filme Entre os muros da escola. ProPosições [online]. vol. 22, n.3, 2011, pp. 113-130.

FONSECA, F.S.R.; OLIVEIRA, L.G. Concepções de meio ambiente dos educadores ambientais do Zoológico de Goiânia: implicações nas atividades e contribuições para a formação do sujeito ecológico?. Educ. rev. [online]. 2011, n.41, pp. 231-246. ISSN 0104-4060. Disponível em: <http://www.scielo.br/pdf/er/n41/15.pdf> Acesso em: 2012.

GOLDBERG, L.G.; YUNES, M.A.M.; FREITAS, J.V. O desenho infantil na ótica da ecologia do desenvolvimento humano. Psicol. estud. [online]. 2005, vol.10, n.1, pp. 97-106. ISSN 1413-7372. Disponível em: <http://www.scielo.br/pdf/pe/v10n1/v10n1a11.pdf> Acessado em 30/06/2012

GRUBITS, S. A casa: cultura e sociedade na expressão do desenho infantil. Psicol. estud. [online]. 2003, vol.8, n.spe, pp. 97-105. ISSN 1413-7372.

KIDNER, D.W. Nature and Human Intelligence. Society for Human Ecology, Human Ecology Review, Vol. 6, No. 2, 1999 pp. 10-22.

LUCENA, M.M.A.; FREIRE, E.M.X. Percepção ambiental sobre uma Reserva Particular do Patrimônio Natural (RPPN), pela comunidade rural do entorno, semiárido brasileiro. Educação Ambiental em Ação. Vol. 35, 2011.

LUZ, C.F.S. et al. As concepções sobre a Caatinga em um grupo de professores da rede Municipal de Iramaia - Bahia. Disponível em: $<$ www.foco.fae.ufmg.br/viienpec/index.php/enpec/viienpec/paper/viewFile/1435/ 545> Acesso em: 09/08/2012.

MARQUES, J. Ecologia da Alma. Petrolina: Franciscana, 2012.

MARQUES, J. (Org.). As Caatingas: Debates sobre a Ecorregião do raso da Catarina. Paulo Afonso: Fonte Viva, 2007.

MOSCOVICI, S. Representações Sociais: Investigações em psicologia social. 3a ed Vozes: Petrópolis, 2005

PEREIRA, L.T.K. O desenho infantil e a construção da significação: um estudo de caso. Disponível em:

$<$ http://portal.unesco.org/culture/en/files/29712/11376608891lais-kruckenpereira.pdf/lais-krucken-pereira.pdf $>$. Acesso em: 30/06/2012 do desenho. Linhas [Online], Vol. 13, nำ 1, UDESC, 2012

Revbea, São Paulo, V.9, Nº 2: 254-269, 2014. 
SALLES, L.M.F. Infância e adolescência na sociedade contemporânea: alguns apontamentos. Estud. psicol. (Campinas) [online]. 2005, vol.22, n.1, pp. 33-41.

SANTANA, J.A.S.; SOUTO, J.S. Diversidade e Estrutura Fitossociológica da Caatinga na Estação Ecológica do Seridó-RN. Revista de biologia e ciências da terra. Vol. 6- Número 2 - 2 Semestre, 2006.

SANTOS, M. 1992: A redescoberta da Natureza. Estud. Av. [online]. vol.6, n.14, 1992, pp. 95-106.

SARAVALI, E.G., GUIMARAES, T. Ambientes educativos e conhecimento social: um estudo sobre as representações de escola. Educ. Rev. [online] vol. 26, n.1, 2010 pp. 157-184.

SILVA, R.M.A. Entre dois paradigmas: combate à seca e convivência com o semi-árido. Soc. estado. [online] vol.18, n.1-2, 2003, pp. 361-385.

SILVA, S.M.C. Condições sociais da constituição do desenho infantil. Psicol. USP, São Paulo, v. 9, n. 2, 1998.

SILVA, T.C.; MEDEIROS, P.M.; ARAÚJO, T.A.S.; ALBUQUERQUE, U.P. Northeastern Brazilian students' representations of Atlantic Forest fragments. Environ Dev Sustain. 12, 2010, pp.195-211.

SILVA, T.S.; CANDIDO, G.A.; FREIRE, E.M.X. Conceitos, percepções e estratégias para conservação de uma estação ecológica da Caatinga nordestina por populações do seu entorno. Soc. nat. (Online) [online]. vol. 21, n.2, 2009, pp. 23-37.

VIGA, M.D.; DICKINSON, F.; CANTO; PILAR.; CASTILLO, M.T. The Impact of Training in Participatory Research on the Behavior of School Children: An Experiment in Yucatan.. Human Ecology Review, Vol. 6, No. 2. Society for Human Ecology, 1999 pp. 62-71. 